\title{
The Canadian experience
}

\author{
Brian Ferguson, Consultant Psychiatrist, Mapperley Hospital, Nottingham NG3 6AA
}

A previous article in the Bulletin describes the 'BTC' (Been to Canada) scheme sponsored by the Nova Scotia Department of Health to bring psychiatric trainees to Canada in order to undertake a year's clinical work in addition to ongoing medical education under the auspices of the Department of Psychiatry at Dalhousie University. Over the years the scheme has attracted a number of graduates, some of whom have been prompted to stay on and develop rewarding careers. The original article by Munro and colleagues (1987) describes the programme from the sponsor's perspective and might well be complemented by this account from a BTC graduate who has now returned to the National Health Service.

The health care services in Nova Scotia are not in many ways dissimilar from those in the United Kingdom. The province joined the Federal Medical Insurance Scheme in 1967 and since then all hospital and most general practice services are funded from a $10 \%$ sales tax and are provided free of charge to the user. Out-patients are, however, liable for the cost of their medications but a variety of mechanisms including insurance and welfare schemes alleviate the burden to a large extent. Most doctors in Nova Scotia work in private practice and receive their remuneration from the State on a fee-per-item basis. Salaries vary considerably between practitioners and can be substantially better than those received by their British counterparts. Psychiatrists employed directly within hospital-based services receive a more modest salary but this can be supplemented by earnings from private practice once Canadian registration and specialist qualifications have been obtained. Before that can be done relevant psychiatric experience, particularly that obtained in general hospital settings in the UK, has to be assessed and various examinations passed; a complex and difficult process that may take about two years.

Recruitment of psychiatrists has traditionally been difficult in the areas of Nova Scotia which are furthest away from the provincial capital, Halifax. Such is the case on Cape Breton Island which has a population of 150,000 , most of whom live in industrial conurbations surrounding the City of Sydney where I spent a year employed on the scheme. The Island offers a magnificent accoutrement of natural beauties: large forests interrupted by lakes and rivers, a coastline with romantic names for the numerous bays, inlets and fishing villages dotted all around it, such as Ingonish and Chetticamp. The psychiatric hospital on the Island is situated in Sydney itself and runs a series of satellite psychiatric clinics which despite their 'community' titles are all hospital based. There is NO requirement for staff to leave the office or ward! The word community in that context is used to denote their proximity to the population served compared to the distance to the principal psychiatric hospital in Halifax 250 miles away where they would previously have received treatment.

The psychiatric clinics themselves have been able to compensate for the lack of trained medical staff by attracting a number of high calibre non-medical personnel including psychologists, social workers and nurses, many of whom have PhDs and Master's degrees. They bring a great deal of highly specialised treatments not frequently seen in peripheral services elsewhere and which are best epitomised by the large number of research projects which are constantly under way, albeit on a small scale. In the absence of medical staff they have in some ways taken over the role that doctors normally have assumed in those clinics. Inevitably newly arrived psychiatrists from the United Kingdom will need time to adjust to the dominance of non-medical leadership. Not infrequently they find it necessary to develop a very different, less influential, role within the multidisciplinary team from that which they might have imagined before arrival. In time, however, their skills and input can find its place and there are plenty of opportunities for good working relationships.

The most welcome aspect of clinical work on the island is the involvement of families who actually seek to support and care for their mentally ill relatives. Extended families will frequently reach out to more distant relatives in order to help in any way they can. On the less attractive side is the unusually quick resort to compulsory admission. For example, of 1,050 admissions to Cape Breton Hospital in 1986, $54 \%$ were admitted under powers of the Mental Health Act, and this figure is only marginally lower for Nova Scotia as a whole. One of the obvious reasons for this is that mental health legislation describes psychiatric disorder as "any disease or disability of the mind and includes alcoholism and drug addiction" (Hospitals Act, 1984). This, not surprisingly, results in the admission of patients who are simply inebriated and who would otherwise be dealt with by social or possibly punitive measures in the United Kingdom. Compulsory admission is also 
used to deal with aberrant behaviour associated with acute emotional disturbances and probably reflects the fact that psychiatrists do not carry out community-based assessments so that the presumed case of mental disorder must first be compelled to enter hospital before a more detailed specialised assessment can be carried out.

Another fascinating aspect of psychiatric practice on the Island is the multi-cultural nature of the society. Because such a large proportion of the Canadian population lives close to the United States, we tend to see them as being very similar to their southern neighbours. The population of Nova Scotia, however, is very diverse. Most residents are descendents of Scottish, English and other European settlers and in many ways behave similarly to their counterparts anywhere in the New World. A distinctive group, however, are the Arcadian French who live in their own community on the eastern part of Cape Breton and who have maintained the use of their own dialect and customs. Although English is their second language it is used colloquially in a fashion that makes it difficult for an Englishspeaking psychiatrist to understand. In particular, the assessment of the nature and depth of affective symptoms can be problematic. The greatest difficulty comes, however, in understanding and assisting the indigenous Mic Mac people. Their language is very different in structure from the European languages and has few single adjectives to describe mental states. Elaborate phrases borrowed from nature can be used which, when translated into English, are difficult to interpret. In particular, formal thought disorder and delusional content may be completely missed. On a practical level it is almost impossible to get somebody to translate accurately the words of a sick relative, apparently from fear that such deranged utterances may bring disgrace to the tribe. The view of Indians as drinkers who indulge in asocial activities may unfortunately also come into play in diagnosis with the resultant tendency to diag- nose alcoholism in place of more significant Axis 1 disorders.

For most psychiatric conditions, however, the usual clinical practices will be familiar to UK trained doctors. The one exception is perhaps the use of the concept of Therapeutic Motor Control (TMC). This is a procedure that was used for potentially disturbed patients. It involves the application of strait-jackets with the arms tied across the body and secured to a chair which is then fastened by bolts to the ground. Patients deemed potentially dangerous could be confined in this way for months on end during their waking hours. More latterly, however, there has been a realisation that there are more appropriate psychopharmacological techniques which can be used to deal with these problems.

Overall, the experience on the BTC scheme can be a very rewarding and worthwhile one. Considerable insight is afforded into psychiatry in a multi-cultural setting. It is intriguing to watch the effect that different social values have on clinical practice and because of relatively cheap and effective communications offers a good platform from which to explore other North American centres. Meeting new friends and the marvellous languid life-style close to nature was very refreshing. The arrangements which have to be made to satisfy all the regulations for visas and temporary licences can be cumbersome, but in the end are certainly worth it. Perhaps one factor which may eventually lead the trainee to return to the bosom of the NHS is the desire to get back to principles of community psychiatry which paradoxically are increasingly under attack here. Perhaps the 'BTC' offers a vision of a world to come?

\section{References}

Hosprtals ACt (1984) Chapter 249. Halifax, Nova Scotia: Queen's Printer.

Munro, A., MCCormick, W. O. \& ArChibald, D. W. (1987) Achieving the BTC Qualification. Bulletin of the Royal College of Psychiatrists, 11, 305-306. 